\title{
La información catastral como herramienta para el análisis de la exposición al peligro de inundaciones en el litoral mediterráneo español
}

\author{
Alfredo Pérez-Morales. Universidad de Murcia, Murcia, España. \\ Salvador Gil-Guirado. Yale University, New Haven, CT, Estados Unidos. \\ Jorge Olcina. Universidad de Alicante, Alicante, España.
}

RESUMEN | El análisis de riesgo en áreas urbanas es una exigencia legal en España. La normativa estatal del suelo y las autonómicas de ordenación territorial y urbanística contemplan la obligación de incluir cartografía de riesgo en los procesos de planificación. En las últimas tres décadas, el riesgo frente a inundaciones se ha incrementado notablemente en algunas regiones españolas en relación con la ocupación de áreas inundables con usos residenciales. La información catastral se convierte en una herramienta eficaz para la valoración de la exposición al peligro de inundaciones. En este artículo se analiza la potencialidad de esta información y su integración con la cartografía del Sistema Nacional de Cartografías de Zonas Inundables en un área del litoral mediterráneo que ha experimentado un incremento desaforado de su parque de viviendas, como método de trabajo aplicable en otros territorios para la valoración de la exposición al riesgo y la elaboración de cartografía de detalle.

PALABRAS ClaVE | planificación territorial, riesgos naturales, vulnerabilidad.

ABSTRACT | Risk analysis in urban areas is a legal requirement in Spain. The state legislation of land and various regional regulations of territorial and urban planning include an obligation to produce maps showing the risk in land use processes. In the last three decades flood risk has increased significantly in some Spanish regions due to an increase in human occupation of flood-prone areas. Cadastral data becomes a powerful tool for the assessment of exposure to flood hazards. This paper analyzes the potential of this information and its integration with the maps of National Cartographic System of Flood Zones in an area of the Mediterranean coastal region that has experienced a significant increase in its housing stock. This method of analysis is applicable to other territories for the assessment of exposure to risk and the elaboration of detail mapping.

KEY WORDS | territorial planning, natural risks, vulnerability.

Recibido el 8 de febrero de 2015, aprobado el 12 de septiembre de 2015

E-mail: A. Pérez-Morales, alfredop@um.es | S. Gil-Guirado, salvagguirado@hotmail.com | J.Olcina, jorge.olcina@ua.es 


\section{Boom inmobiliario en Espańa y aumento de la exposición al riesgo de inundaciones}

La mejora de las condiciones socioeconómicas en los países desarrollados y la aplicación masiva de las medidas de mitigación de impactos denominadas "estructurales", han permitido elevar los límites de seguridad y disminuir notablemente el número de víctimas ocasionadas por las inundaciones (Barredo, 2009). No obstante, las tres últimas décadas han conocido un incremento en el volumen de pérdidas económicas ocasionadas por episodios de inundación (World Meteorological Organización [wмо], Centre for Research on the Epidemiology of Disasters [CRED] \& Université Catholique de Louvain [UCL], 2014), que podría venir asociado a un aumento de la exposición (seres humanos, actividades económicas, infraestructuras) a este peligro natural. Es probable que las actuaciones humanas poco acordes con los rasgos naturales del medio hayan provocado una acentuación general del riesgo (Changnon, Pielke, Changnon, Sylves \& Pulwarty, 2000; Bouwer, Crompton, Faust, Hoppe \& Pielke, 2007, Barredo, 2009; Olcina, 2009). Ante este escenario, resulta preocupante el futuro próximo, ya que no parece que vaya a mejorar este estado de cosas, puesto que las proyecciones de cambio climático seńalan un posible incremento de eventos atmosféricos extremos a consecuencia del calentamiento térmico planetario (Intergovernmental Panel on Climate Change [IPCC], 2012).

En este contexto, algunos territorios, por sus condiciones fisico-ambientales y la intensa transformación del espacio geográfico experimentada en las últimas décadas, se han convertido en regiones-riesgo, con alto grado de vulnerabilidad de su población ante el desarrollo de episodios extremos, como las inundaciones. Es el caso de Espańa, reconocido como uno de los territorios europeos con mayor grado de riesgo frente a peligros de la naturaleza (Saurí, Serra, Olcina \& Vera, 2011), particularmente a inundaciones. Desde la segunda mitad del siglo xx, el acelerado desarrollo experimentado ha convertido este territorio en un escenario de actuaciones que, en la búsqueda del progreso colectivo, no valoraron, en más ocasiones de las deseables, la exposición de personas, bienes y servicios al peligro, con la consiguiente mayor frecuencia de episodios de inundación con efectos negativos para la población (Gil-Guirado, Pérez \& Barriendos, 2014; Gil-Guirado, Pérez, López \& Barriendos, 2014), lo que a la postre ha aumentado las pérdidas económicas de manera significativa (Barredo, Saurí \& Llasat, 2012).

En este ámbito geográfico concreto, el crecimiento urbano normal se ha visto fuertemente impulsado por el aumento en la demanda de viviendas secundarias para vacaciones, o residenciales, por parte de turistas nacionales y, sobre todo, extranjeros (Burriel, 2008). Durante el periodo 2001 a 2011, el número de habitantes centroeuropeos y nórdicos que se instalaron en las provincias de la costa mediterránea ascendió un 481\%, lo que supone un total de 477.325 nuevos habitantes, superando de forma significativa el crecimiento experimentado por la población española, 110,5\% para el mismo intervalo de tiempo (Instituto Nacional de Estadística [INE], 2013). La llegada de esos nuevos residentes disparó la cifra de nuevas construcciones entre 1970 y 2013 en más de un 233,24\% en cuanto a los inmuebles de carácter residencial, y en un $317 \%$ el total de ellos (Dirección General de 
Arquitectura, Vivienda y Suelo [DGAVs], 2014). Para dar idea de la repercusión que tuvo dicho fenómeno a escala nacional, de todo lo que se construyó en España para el periodo mencionado, el $43,9 \%$ de los edificios y $40,7 \%$ del total de la superficie se llevó a cabo en el litoral mediterráneo (figura 1).

Resulta especialmente dinámica la actividad de la construcción en las provincias de Alicante y Murcia. Durante el periodo de estudio (1975-2013), la población aumentó en torno a un $215 \%$, mientras que el número de casas lo ha hecho en un $373 \%$ (INE, 2013). La tendencia edificatoria experimentada por Alicante antes de la crisis de 2008 pronto la situó en el tercer puesto del ranking nacional tras las provincias de Madrid y Barcelona, por encima de otras de mayor entidad de población, como Valencia o Málaga. Incluso, si consideramos de forma conjunta la significación del fenómeno en la franja litoral de Alicante y Murcia, este espacio geográfico de menos de $5.000 \mathrm{Km}^{2}\left(4.611 \mathrm{Km}^{2}\right)$ acoge algo más de 1,6 millones de habitantes (1.638.819 según datos del INE, 2013), y ocuparía la segunda posición nacional en incremento de la actividad constructiva, tan solo por detrás de la capital del Estado.

FIGURA I | Expansión residencial en España (2001-2012)

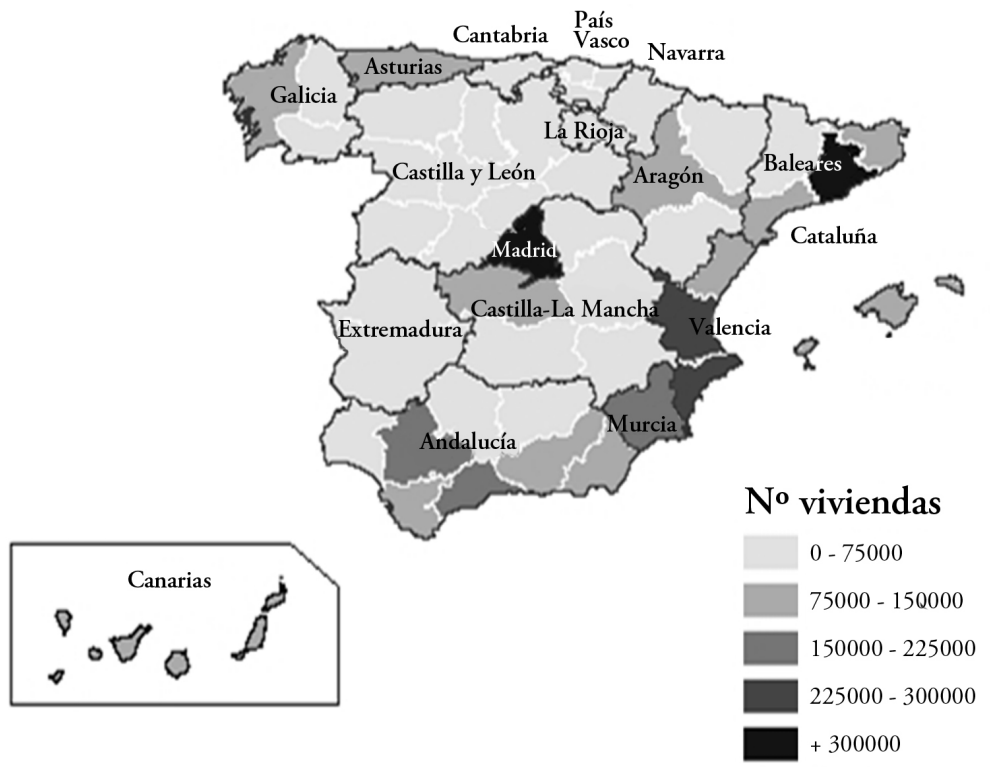

FUENTE ELABORACIÓN PROPIA A PARTIR DE DATOS DEL MINISTERIO DE FOMENTO, ESTADÍSTICAS DE VIVIENDA

A escala municipal, el análisis es todavía más ilustrativo. Así, durante la década de los noventa, seis de los diez municipios con mayor volumen de viviendas visadas estaban situados en el litoral mediterráneo, correspondiendo los dos primeros lugares del ranking a las localidades alicantinas de Torrevieja y Guardamar del Segura. Además, entre los 55 municipios con mayor número de ese tipo de viviendas durante el periodo 1992-2000 en relación con la población existente en 
ellos en 1991, un total de 38 estaban situados en primera línea de costa (Olcina, 2007). Este desarrollo se evidencia de forma más clara en el hecho de que en algunos de estos ámbitos locales se ha producido un incremento absoluto en el número de viviendas construidas, mayor que en la propia capital provincial; es el caso, por ejemplo, de Torrevieja y Orihuela en la provincia de Alicante. Asimismo, existe una serie de municipios litorales de tamaño medio donde la dinámica de crecimiento urbanístico presenta tasas similares a las de su capital, como en el caso de San Javier, Mazarrón y Águilas en Murcia.

A efectos del presente trabajo, encontramos una prueba importante de la relación positiva del aumento de lo construido y las inundaciones precisamente en las provincias de Alicante y Murcia. Tal y como indican las series de episodios y pérdidas, la exposición y el número de inundaciones han ascendido paralelamente y de forma exponencial para el periodo 1960-2013 (Gil-Guirado, Pérez, López \& Barriendos, 2014), entendiendo exposición como la población y el valor de los bienes en riesgo de inundación (Kron, 2005; IPCC, 2014). Es decir, a pesar de las costosas inversiones en prevención y protección contra el riesgo de inundaciones, los daños económicos causados por las lluvias torrenciales siguen experimentando una tendencia creciente. Según Gil-Guirado, Pérez, López y Barriendos (2014), entre 1975 y 2013 se produjeron 191 eventos de inundación en el área de estudio, una tasa de 4,9 inundaciones por ańo, mientras que para el periodo de 1960 a 1974 , la tasa había sido de 2,2 inundaciones por año.

Se trata de un problema creciente que, en España, se ha ido concretando en unas propiedades físicas cada vez más definidas. A diferencia de otros países de Centroeuropa, como Holanda, Francia o Alemania (wMo, CRED \& UCL, 2014), las características del territorio español sometido al riesgo de inundación han ido alejándose de la configuración tradicional del desbordamiento de un gran cauce fluvial y predominan los episodios acontecidos en pequeñas cuencas hidrográficas de comportamiento violento y espasmódico. En esta diferenciación mucho ha tenido que ver la política de defensa contra avenidas e inundaciones en España. Esta política se ha basado tradicionalmente en las actuaciones estructurales como medida prioritaria de protección, lo que supuso asegurar, por medio de presas y canalizaciones, las principales ciudades atravesadas por grandes ríos. En principio, esas obras parecen haber garantizado hasta el momento unos umbrales de seguridad que, aunque en algunos casos no han sido puestos todavía a prueba, parece que responden a las pretensiones con las que se abordaron. Sin embargo, el proceso de ocupación intenso hasta ahora comentado, especialmente en el litoral, supuso una migración del riesgo hacia esos ámbitos hasta entonces desprotegidos y carentes de obras de defensa. Desde la década de 1970, las inundaciones más severas registradas tienen una característica en común: la de ser inundaciones-relámpago, a menudo torrenciales (Consorcio de Compensación de Seguros, 2015). En este tipo de fenómenos, la magnitud de la crecida o la avenida que lleva al desbordamiento, medida en términos de caudal por $\mathrm{Km}^{2}$, es muy superior a la de los ríos que drenan grandes cuencas -de ahí su mayor severidad-, y tienen un tiempo de presentación mucho más rápido tras la lluvia, normalmente pocas horas, frente a los días que tarda una avenida en recorrer un gran río. En este tipo de situaciones las medidas de 
mitigación estructurales parecen perder su efectividad y otorgar protagonismo por descarte a las de planificación.

En la actualidad, parece existir un consenso generalizado en que el planeamiento es la medida preventiva más lógica, adaptativa y rentable para alcanzar una mitigación de las pérdidas causadas por inundaciones. Sin embargo, no es del todo infalible y así ha sido discutido por varios autores (Abbot, 2005; Borup, Brown, Konrad \& Van Lente, 2006; Luhman, 1979; De Roo, 2003; De Roo \& Porter, 2007). Durante el proceso de toma de decisiones que conlleva cualquier tarea de planeamiento, se suele abrir el debate entre las expectativas y la incertidumbre. La ordenación territorial es una actividad orientada al futuro que implica que no se sabe cómo evolucionarán los resultados que ella produzca; es decir, obviamente cuenta con un alto grado de incertidumbre. Desde esta perspectiva, para que las acciones sean significativas, requieren que los actores desarrollen expectativas con respecto a eventos contingentes, y que tales expectativas sean capaces, a su vez, de influir en las interpretaciones de la realidad y en la orientación de las acciones, pero que sean también una manera de frenar dicha incertidumbre. Ante esta circunstancia conviene reforzar los procesos de planeamiento por medio del uso de aproximaciones técnicas que, aunque por el momento sencillas y aplicadas tan solo a procesos lineales, pueden mejorar sustancialmente la eficiencia en las decisiones territoriales.

En este sentido, si atendemos a la cuestión específica de las inundaciones, gracias a la mayor precisión que ofrecen los resultados de estudios de inundabilidad, resulta interesante su implementación en las tareas de planificación. Lo anterior debe entenderse como una aplicación de tales herramientas de forma dinámica, lo que permitiría diagnosticar e identificar las posibles variaciones que se produzcan en el territorio administrado y, a la postre, reducir significativamente el grado de incertidumbre antes señalado.

Existen precedentes de varios trabajos que demuestran que los modelos del peligro pueden ser combinados de forma satisfactoria con datos espaciales acerca de las edificaciones expuestas. Desafortunadamente, este tipo de avances no se han podido desarrollar de forma generalizada debido, principalmente, a la falta de disponibilidad de información y las altas exigencias en cuanto al cálculo de dichas modelizaciones. Para cubrir estas carencias, muchos países basan sus decisiones sobre mitigación del riesgo en sus planeamientos por medio de la estimación de tasas de crecimiento de pérdidas a partir de series de datos más o menos largas sobre pérdidas económicas, a nivel nacional (Meyer et al., 2013) e internacional (Van Renssen, 2013). Sin embargo, los responsables en la gestión del territorio han depositado el grueso de su confianza en el análisis de riesgo utilizando información agregada de los usos del suelo (por ejemplo, Bouwer et al. 2007; De Moel, Aerts \& Koomen, 2011; Te Linde, Bubeck, Dekkers, De Moel \& Aerts, 2011; Jongman, Ward \& Aerts, 2012a; Poussin, Bubeckm Aerts \& Ward, 2012; Rojas, Feyen \& Watkiss, 2013; Koks, De Moel, Aerts \& Bouwer, 2014). El problema de estos enfoques es que parecen limitados en cuanto a su capacidad de diagnóstico espacial concreto (De Moel \& Aerts, 2011; Jongman et al., 2012b). Afortunadamente, los trabajos de este tipo han mejorado gracias a los avances experimentados en la digitalización del espacio construido por parte de los organismos oficiales (Jongman, 
Koks, Husby \& Ward, 2014). Mediante estas herramientas de información espacial, se puede analizar con una gran precisión el grado, la intensidad y el volumen de lo expuesto en áreas de riesgo de inundación. De forma derivada, este tipo de tareas revela el reducido grado de adaptación a las inundaciones materializado a través de la escasa eficiencia de las medidas de mitigación de la exposición al peligro, por la supeditación del bien común a los poderes económicos y políticos (Jiménez, 2009).

El presente trabajo aborda el análisis del incremento de la exposición al peligro de inundaciones en el espacio litoral mediterráneo de los municipios de Alicante y Murcia, con objeto de mostrar la potencialidad que ofrece la información catastral como herramienta para el análisis de riesgo y la elaboración de cartografía de detalle. Se ha escogido este territorio porque la franja litoral de estas dos provincias es un ejemplo paradigmático, por sus características singulares de crecimiento urbano y la estrecha relación de lo anterior con las pérdidas económicas por efecto de las inundaciones.

\section{Análisis del aumento de la exposición ante inundaciones: la potencialidad de la información catastral}

Para la evaluación de la exposición frente a inundaciones, es necesaria la consideración espacial de dos factores: el componente físico (peligrosidad natural) y el humano (Cardona et al., 2012). La información sobre el primero se ha obtenido de los datos contenidos en el Sistema Nacional de Cartografía de Zonas Inundables (sNCZI), del Ministerio de Agricultura, Alimentación y Medio Ambiente (Magrama, 2014). Se trata del instrumento oficial elaborado por dicho Ministerio, que, siguiendo los principios de la Directiva 2007/60 sobre evaluación y gestión de riesgos de inundación, se emplea en la gestión del espacio fluvial, la prevención de riesgos y la planificación territorial. Esta fuente proporciona los resultados de las modelizaciones hidrológicas en formato vectorial para los siguientes periodos de retorno: 10 años (PRIO); 50 años (PR5O); 100 ańos (PRIOO); y 500 ańos (PR5OO). Una vez situados sobre el terreno, se confecciona el mapa de zonas inundables.

Para el análisis del componente humano, se consideraron las edificaciones en forma de parcelas catastrales, ${ }^{1}$ siguiendo la metodología propuesta por García (2013). Esta información se obtuvo de la sede electrónica de la Dirección General del Catastro, dependiente del Ministerio de Hacienda y Administraciones Públicas (MHAP) con datos actualizados a mayo de 2013 (MHAP, 2014). Los productos catastrales que se consultaron fueron las parcelas de naturaleza urbana ${ }^{2}$ para cada municipio del área de

$1 \longdiv { \text { La parcela es la unidad de desagregación máxima utilizada en este trabajo y corresponde, por regla } }$ general, a cada edificación localizada sobre el terreno.

2 Siguiendo la distinción de tipos de bienes inmobiliarios según la naturaleza del suelo establecida en el Real Decreto Legislativo (RDL) 1/2004 por el que se aprueba el texto refundido de la Ley del Catastro Inmobiliario (Boletín Oficial del Estado [вов] 8/03/2004), las descargas de cartografía pueden realizarse de los suelos de naturaleza urbana y de los de naturaleza rústica. De acuerdo con los artículos 6, 7 y 8 de dicho texto refundido, se entiende como suelo de naturaleza urbana, de manera simplificada, "el clasificado o definido por el planeamiento urbanístico como urbano, urbanizado o equivalente" y "los que tengan consideración de urbanizable”. El suelo de naturaleza rústica es "aquel que no sea de naturaleza urbana, ni esté integrado en un bien inmueble de 
estudio. Los datos catastrales vienen en formato alfanúmerico e incluyen toda la información del catastro, excepto la sujeta a confidencialidad. La información se organiza en una sucesión de registros con tamaño individual de 1.000 caracteres. Cada uno de ellos contiene información codificada, en la que se encuentra el año de construcción de cada unidad o parcela catastral. Por su parte, la cartografía está compuesta por una serie de polígonos que representan las mencionadas parcelas catastrales. Los polígonos vienen acompańados de una tabla de atributos con información detallada sobre las características de los mismos e identificados mediante el campo Referencia Catastral. Gracias a ese registro oficial de cada parcela, todos los datos referentes a la antigüedad de lo construido anteriormente seńalados, se incorporan a la tabla de atributos mencionada mediante el gestor de la base de datos de un sistema de información geográfica (sIG) y se obtiene el mapa del factor humano.

A partir de la combinación de las dos componentes principales, área inundable y edificaciones, es posible obtener el mapa de exposición. Este valioso documento nos ayuda a determinar la localización de lo expuesto según su probabilidad de ocurrencia de una avenida.

A pesar de las bondades de las fuentes manejadas, se tuvo que hacer frente a una serie de limitaciones asociadas a la propia naturaleza y características de las mismas. En lo referente a los datos catastrales vinculados a parcelas, se detectó que, en algunos casos, una misma parcela catastral puede contener más de un edificio construido en distintos años. En esos casos se tomó el año de la edificación más antigua. De esta manera, asumimos que no hay propiedades antiguas que hayan sido demolidas o sustituidas por unas más nuevas, lo cual nos podría llevar a una infraestimación del número de parcelas en los primeros ańos de la serie. Para el caso de las edificaciones del área de estudio donde se evidenció dicho error, se calculó su valor final tanto para las edificaciones expuestas como las no expuestas, tal y como se resume en la tabla 1.

TABLA I | Porcentaje de error de las parcelas que contienen más de una edificación y el total de parcelas catastrales del área de estudio diferenciadas entre las expuestas y las no expuestas

\begin{tabular}{|l|c|c|}
\hline & TOTAL PARCELAS >I EDIFICIO & TOTAL PARCELAS \\
\hline No expuesto & 18.325 & 308.553 \\
\hline Expuesto & 1.355 & 26.363 \\
\hline No expuesto & \multicolumn{2}{|c|}{$5,94 \%$} \\
\hline Expuesto & $5,14 \%$ \\
\hline
\end{tabular}

FUENTE CATASTRO DE URBANA. ELABORACIÓN PROPIA

características especiales". Esta categoría especial incluye los suelos que "constituyen un conjunto complejo de uso especializado" perteneciente a alguno de los siguientes grupos: destinados a producción energética (refinerías, embalses, etc.), vías de circulación (autopistas, carreteras y túneles de peaje) o aeropuertos y puertos comerciales. 
En segundo lugar, al igual que sucede en otros trabajos de similares características (Jongman et al., 2014), al no disponerse de modelizaciones hidrológicas anteriores a las empleadas en nuestro análisis, se asumió que las zonas inundables de los periodos de retorno han permanecido estables a lo largo del tiempo. Sin embargo, en el ámbito geográfico analizado las transformaciones antrópicas de los cauces fluviales han sido intensas y a buen seguro se habrán alterado en ese periodo (Hooke, 2006).

Por último, durante el desarrollo metodológico para la obtención del mapa de exposición, se hizo frente a una seria dificultad a la hora de evaluar la superficie ocupada en zona inundable. En ocasiones, debido a la mejora en la precisión de las modelizaciones hidrológicas, la zona inundable sigue el trazado de las calles del núcleo urbano y la lámina de agua modelizada no se solapa con el trazado de las parcelas asociadas a edificaciones, por lo que no existe una intersección posible con la zona inundable para detectar las propiedades que resultarían afectadas, pese a que hay constancia de que las partes bajas de esos edificios son las primeras que sufren los impactos ante una inundación potencial (Gil-Guirado, Pérez, López \& Barriendos, 2014). Por tanto, se ha considerado que esos inmuebles pasarían a formar parte de la superficie inundable, realizando para ello un buffer o área de influencia de un metro sobre la parcela catastral.

\section{Resultados: incremento de la exposición a inundaciones en el litoral de Murcia y Alicante}

El incremento en el volumen de pérdidas económicas vinculadas a los episodios de inundación en las últimas décadas es resultado de que algunos procesos de ocupación y urbanización adaptados a los condicionantes ambientales han evolucionado a otros en los que la percepción de dichos condicionantes muchas veces brilla por su ausencia. En el área de estudio, la escasez e irregularidad de las precipitaciones predominantes condicionó las primeras etapas de ocupación de estas tierras a través de fuertes lazos de dependencia y respeto hacia los cursos fluviales más importantes. La práctica agrícola con rendimientos regulares y capaz de atender las necesidades mínimas de sus pobladores se relacionaba, muy directamente, con las posibilidades de aportar a los cultivos agua procedente de esos cauces naturales. La distribución de los yacimientos arqueológicos respalda esta conjetura y evidencia una actitud inicial de los primeros ocupantes que se limitó al desarrollo de un conjunto de medidas para aprovechar esos caudales esporádicos, y un poblamiento que evitaba el peligro de inundación localizándose en espacios elevados (Pérez, 2008).

A medida que esa sociedad fue desarrollándose económica y tecnológicamente, se fue perdiendo el respeto que durante siglos había permitido eludir con cierta habilidad el problema de las inundaciones, y se produjo un incremento de la exposición, acompañado de la frecuencia en el número de catástrofes, que afectaron el territorio en estudio. La confianza depositada en unas supuestas capacidades de resistencia y control de la naturaleza por medio de actuaciones estructurales (presas, canalizaciones, etcétera) motivó, de un lado, el cambio hacia una agricultura de regadío y altamente transformadora del territorio, junto con el abandono de una gran superficie agrícola dedicada al aprovechamiento de aguas pluviales; y de otro, 
en lo relativo a la evolución urbana, la integración forzada de los tramos finales de cursos fluviales y la usurpación de sus lechos de inundación, con los problemas posteriores añadidos que eso implicó. Este tipo de cambios se acentuó, sobre todo, en las últimas décadas, y una muestra de ello se evidencia en los procesos de artificialización registrados en la evolución de los usos de suelo en los últimos años (Symeonakis, Calvo-Cases \& Arnau-Rosalen, 2007). Esto ha sido especialmente intenso y acusado en el ámbito litoral, donde el crecimiento urbano reciente vinculado al desarrollo urbano-turístico ha sido calificado como un auténtico "tsunami urbanizador" (Gaja, 2008). De acuerdo con los resultados de las figuras 2a y 2b, a partir de 1975 el espacio urbanizado y el número de inmuebles que ocupan cada una de las zonas inundables para los periodos de retorno estudiados han ido experimentando un crecimiento acumulado continuo en el litoral de las provincias de Murcia y Alicante.

En cifras relativas, los resultados son verdaderamente alarmantes. Para el periodo analizado, el incremento de las parcelas urbanas es del 347\% $(<1975=100)$, lo que supone una tasa de crecimiento anual del $8,9 \%$. Sin embargo, llama la atención que el crecimiento de las parcelas urbanas en áreas propensas a experimentar inundaciones ha sido mayor que el de áreas no inundables (273\%). En lo que se refiere a la superficie ocupada por edificaciones en terrenos expuestos, los valores de incremento son sensiblemente inferiores $(368 \%)$ con respecto a lo que ha sucedido en zonas no expuestas $(442 \%)$. En cualquier caso, no dejan de ser cantidades muy elevadas, que dan una idea del proceso acelerado de expansión urbanística y de la escasa repercusión que han tenido las medidas de carácter preventivo, como el ordenamiento territorial.

FIgura 2a | Curva de saturación de la superficie construida en zona inundable para los diferentes periodos de retorno

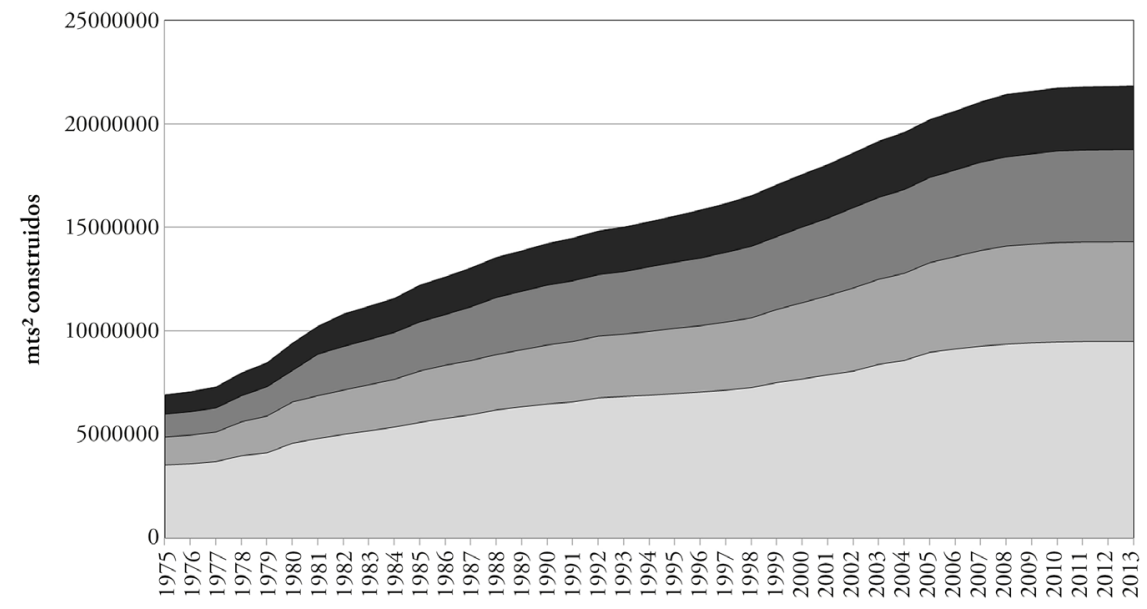

FUENTE ELABORACIÓN PROPIA 
Figura 2B | Curva de saturación de los edificios construidos en zona inundable para los diferentes periodos de retorno

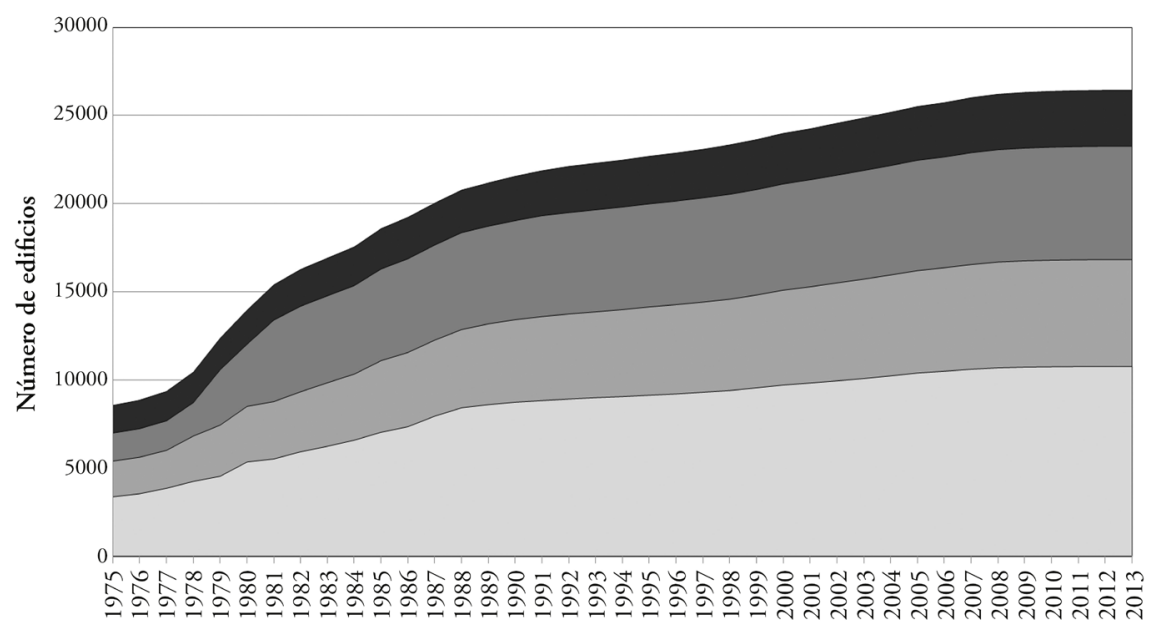

FUENTE ELABORACIÓN PROPIA

El análisis detallado de la figura 3 permite distinguir dos periodos bien diferenciados: $1975-1993$ y 1994-2013. El primero viene precedido por la primera crisis del petróleo en 1973. Pese a la fuerte repercusión que tuvo este acontecimiento y que llevó, en términos globales, a un estancamiento de la economía española durante una década, sus efectos sobre la actividad inmobiliaria fueron efímeros en el ámbito espacial estudiado, fruto de las necesidades habitacionales de una población creciente, junto con la expansión de las viviendas para un sector turístico en continuo crecimiento. De esta manera, a partir de 1977 el crecimiento urbano en espacio inundable y no inundable fue intenso. Las causas principales de esta nueva dinámica deberían buscarse en los cambios que introdujo la mencionada crisis en el modelo económico espańol, con la paulatina terciarización de la economía regional y la progresiva importancia en el PIB estatal del sector servicios (Prados \& Sanz, 1996). Este proceso tuvo especial influencia en las regiones y municipios turísticos como los del área de estudio, ya que ejerció, junto a la entrada de España en la Unión Europea en 1986, un efecto llamada de la población atraída por el impulso de esas actividades (Harrison, 2006), principalmente el turismo, lo que a la postre supuso un aumento en la construcción de edificaciones para satisfacer la llegada de trabajadores y visitantes. Entre 1975 y 1980 se construyó un total de 35.618 nuevos inmuebles en el área de estudio, de los cuales 6.361 (17,8\%) fueron levantados en zona inundable (figura 4a), lo que supone una tasa media de ocupación del espacio inundable (la velocidad a la que se va saturando la superficie inundable) del 0,61\% anual en todas las zonas expuestas, y un máximo de 1,9\% para el PRIo (figura 4b), en lo que fue el momento de ocupación del espacio inundable de mayor intensidad de toda la serie analizada. 
FIgURA 3 | Evolución de la superficie urbanizada en la zona inundable de los diferentes periodos de retorno

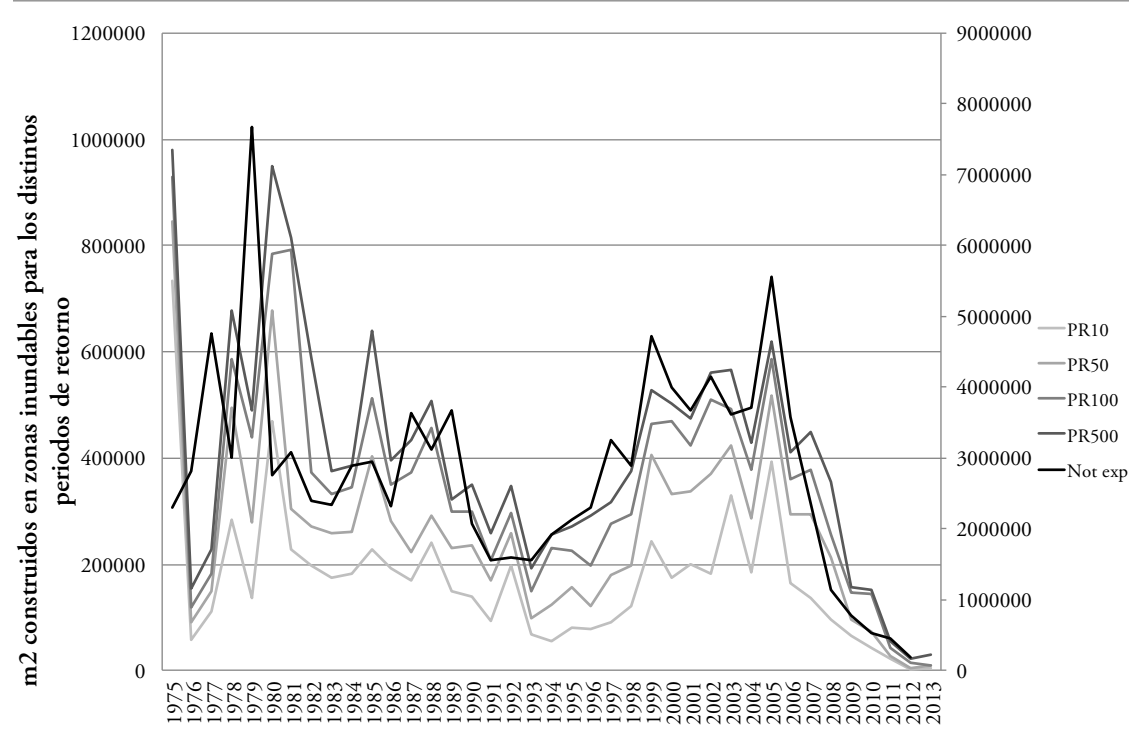

FUENTE ELABORACIÓN PROPIA

A partir de 1980, la tasa de urbanización fue decayendo hasta el 0,1\%, de 1993, para el promedio de todos los periodos de retorno. Este año marca el inicio de otra gran crisis económica (Prados \& Sanz, 1996) y pone fin al primer periodo que, no obstante, había empezado a mostrar signos de agotamiento a mediados de los años ochenta del siglo xx. Además de factores económicos, este cambio pudo deberse a la aplicación de las primeras medidas efectivas de mitigación del riesgo por los municipios litorales espańoles. Estas actuaciones estructurales se desarrollaron como respuesta a la demanda social de soluciones al problema de reiterados episodios de inundación ocurridos en los años ochenta en el litoral mediterráneo (Serra-Llobet, Tàbara \& Saurí, 2013). A ello obedecieron el Plan de Defensa contra avenidas de la cuenca del Segura y las obras de canalización de cauces menores -barrancos y ramblas- llevadas a cabo en diversos municipios del litoral murciano y alicantino.

No obstante, el balance general de este primer periodo se traduce en un aumento de la superficie urbanizada en zona inundable de $9.087 .743 \mathrm{~m}^{2}$, lo que, sumado a lo que ya estaba construido, elevó la cifra a los $15.024 .205 \mathrm{~m}^{2}$. Por su parte, el número de edificios construidos fue el más elevado para el periodo analizado. Se levantó un total de 90.922 inmuebles, de los cuales 14.692 estuvieron localizados en las áreas de influencia de los distintos periodos de retorno. En aquel momento, la disponibilidad de mucho terreno aprovechable para la construcción motivó un modelo de crecimiento urbano atomizado y polinuclear, más extensivo en horizontal que en vertical, al contrario de los sucedido durante el segundo boom urbanístico identificado. 
FIGURA 4A | Evolución del número de edificios construidos en zona inundable de los diferentes periodos de retorno

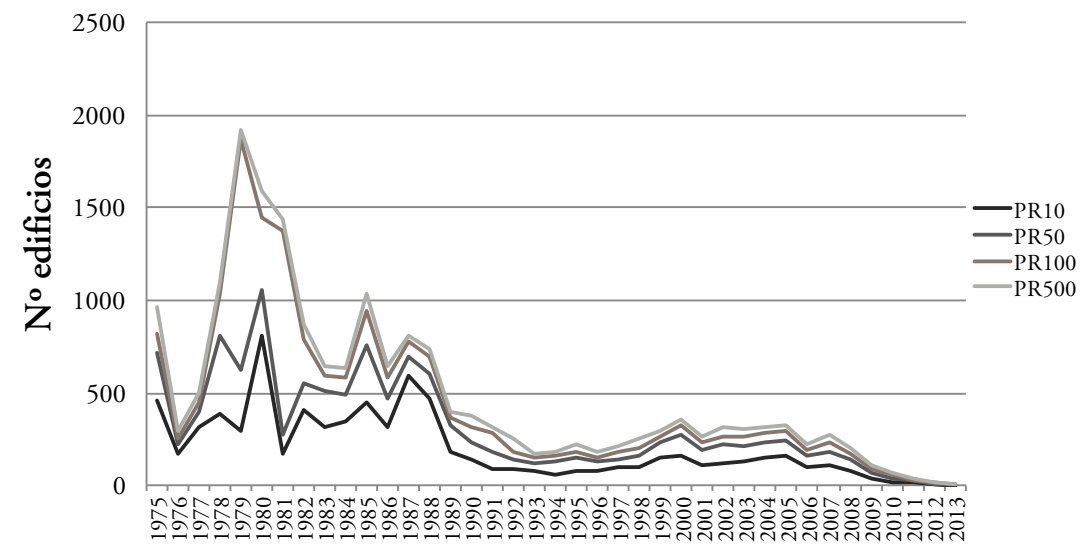

FUENTE ELABORACIÓN PROPIA

FIGURA 4B Evolución del porcentaje de superficie urbanizada en zona inundable para los diferentes periodos de retorno

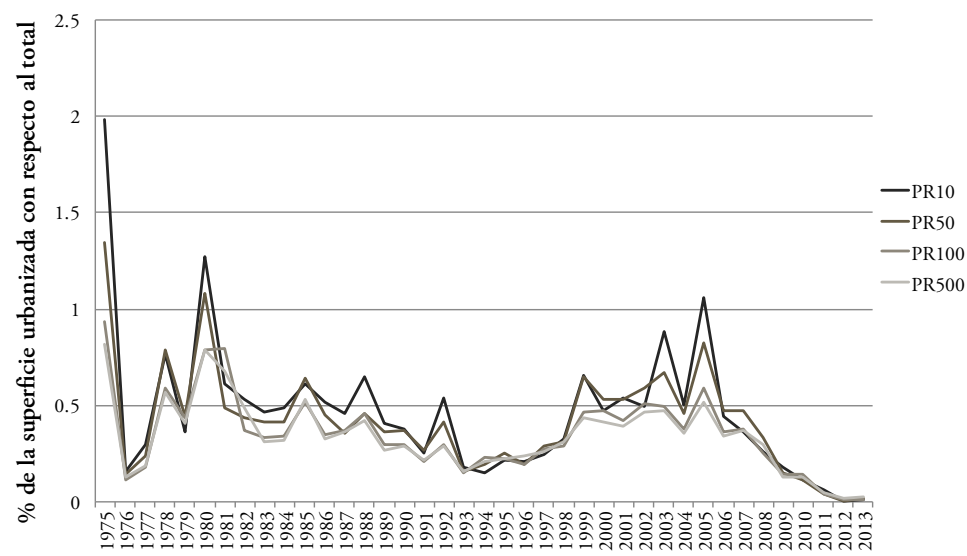

FUENTE ELABORACIÓN PROPIA

La superación de la crisis económica que afectó a España en 1993 y que redujo la actividad inmobiliaria de manera drástica, supuso el inicio del segundo periodo de crecimiento del parque de viviendas, que ha sido el que ha terminado por saturar el espacio inundable en varios de los municipios estudiados. Entre los años 1994 y 1997 se inició este nuevo aumento, pero es sobre todo a partir de 1998 cuando se desató un nuevo proceso desmedido de construcción que, lejos de respetar el límite de los cauces naturales, volvió a contribuir al aumento y acumulación tanto de edificios como de superficie ocupada en zonas inundables por distintos periodos de retorno. Tan solo 
entre 1998 y 2006 se levantaron 2.644 nuevas edificaciones, con una tasa anual de edificación en zona inundable en valores más similares al anterior boom de la vivienda y que situaron a España a la cabeza de Europa por este concepto (Burriel, 2008).

Entre las causas que ayudan a entender la magnitud del fenómeno destacan dos. En primer lugar, la propia liberalización del proceso urbanizador experimentado con la aprobación estatal de la Ley del Suelo de 1998 y de algunas leyes de planeamiento autonómicas y municipales en el ámbito mediterráneo (Jiménez, 2009); así, en algunos municipios del área de estudio (por ejemplo, Torrevieja), la promoción de suelo para su urbanización ha agotado, prácticamente, este recurso en apenas quince años. En segundo lugar, está la demanda de viviendas para residencias de inmigrantes europeos, que fue creciente en el área de estudio, en un contexto de bonanza económica en Europa en esos años. Se trata de un grupo poblacional que, atraído por las suaves condiciones climáticas invernales del litoral mediterráneo y, sobre todo, por una coyuntura económica ventajosa con bajos tipos de interés hipotecario en Espańa (se pasó del 16,6\% en diciembre de 1990 al 4,2\% a mediados de 2006, con valores mínimos del 3,19 en agosto de 2005), llegó de forma masiva a este territorio para adquirir segundas residencias.

En definitiva, este periodo ha supuesto un incremento de $6.813 .211 \mathrm{~m}^{2}$ construidos en zona inundable, que, añadidos a lo que ya había acumulado, dan como resultado una cifra global de $21.837 .416 \mathrm{~m}^{2}$. Esto ha provocado una saturación del espacio inundable que ha motivado diferencias urbanísticas, puesto que durante el boom urbanístico reciente el número de edificaciones construidas en zona inundable fue mucho menor (4.148 entre 1994 y 2013, frente a los 14.692 del periodo comprendido entre 1975 y 1993), lo que indica una mutación del modelo urbanístico hacia el poblamiento en forma de grandes dominios asociados a una única edificación (tabla 2).

El resultado de este proceso de expansión del casalicio durante los 39 años de la serie analizada se ha traducido en la sucesiva integración en el callejero urbano de cursos fluviales y, por ende, el incremento progresivo de la exposición al peligro de inundación. Lo anterior puede advertirse en la distribución de lo construido en los distintos periodos de retorno con respecto al total. La figura 5 ilustra cómo, hasta estos últimos años, la ocupación de lo inundable se ha hecho principalmente sobre la zona de los diez años. Se trata de un dato alarmante, que resulta de un comportamiento corriente en un ámbito geográfico donde la red hidrográfica está compuesta en su mayoría por ramblas y barrancos que de forma natural permanecen secos durante largos periodos de tiempo, y tan solo ven interrumpida esta condición en situaciones transitorias tras lluvias de fuerte intensidad horaria, contribuyendo esto a una baja percepción del peligro de inundación (Llasat, López, Barnolas \& Llasat-Botija, 2008). Desafortunadamente, estas características físicas han invitado desde siempre a ocupar los márgenes más próximos a los lechos de inundación, cuando no a instalar las edificaciones directamente en el fondo de esos cauces fluviales y a desdibujar por completo el trazado original de los mismos. Esta forma de expansión urbana delata una grave situación de negligencia por parte de las administraciones locales, al haber permitido usos residenciales en zonas de inundación frecuente. 


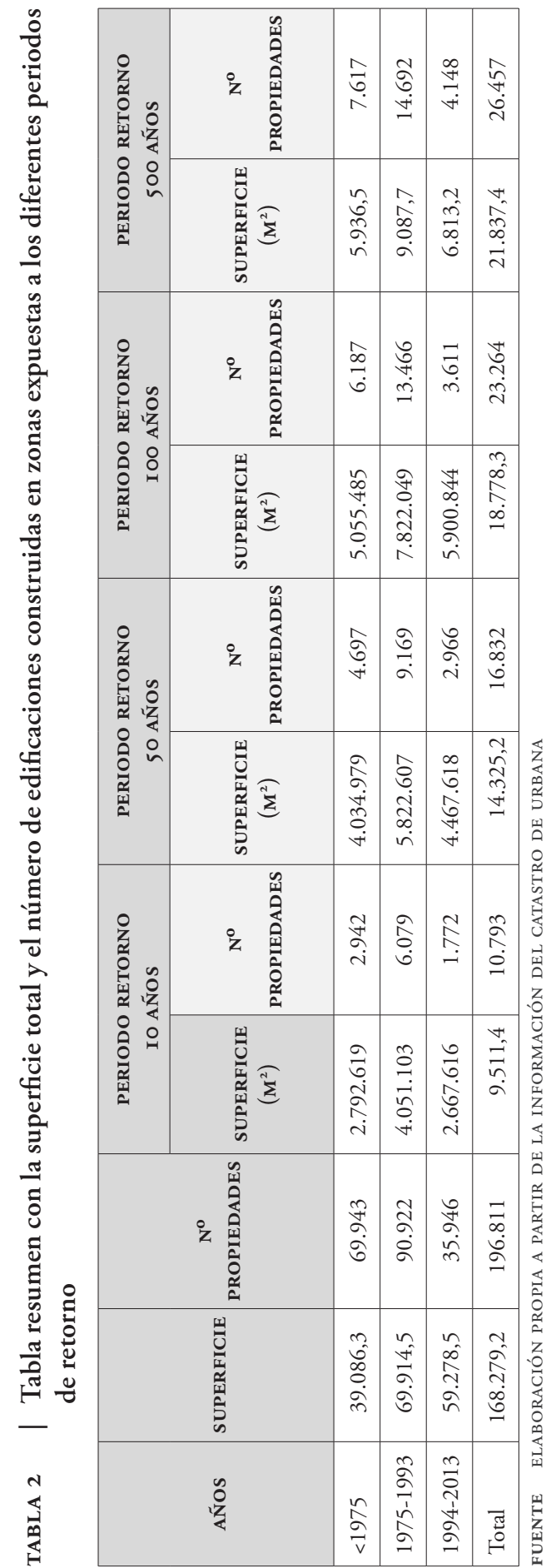


FIGURA 5 Evolución del porcentaje construido en cada periodo de retorno

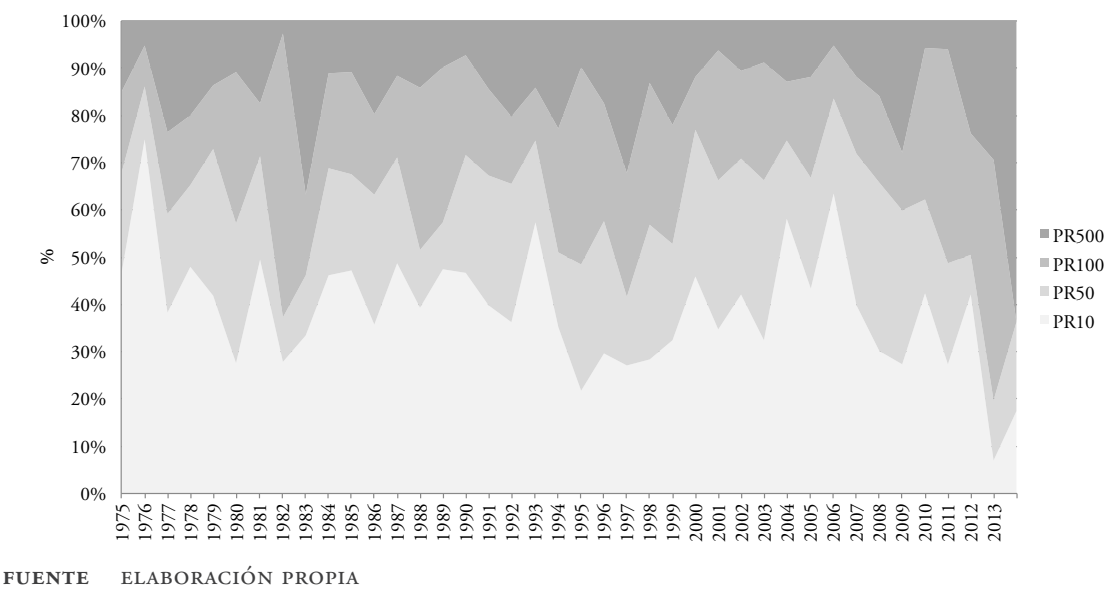

La figura 6 ilustra la tendencia seguida por la superficie construida en zona inundable con respecto al total construido. Se advierte una variabilidad que se ajusta a las coyunturas de crisis y crecimiento señalados. No obstante, la línea de tendencia de la superficie expuesta indica un descenso algo mayor que la de la superficie no expuesta. Este hecho estaría en relación con la mencionada ocupación intensiva de los espacios de riesgo en las décadas anteriores (1970 a 1990) respecto a la última fase de fuerte crecimiento inmobiliario y al efecto que han podido tener las restricciones legales de ocupación de áreas de riesgo (leyes del suelo 1998, 2008, 2015 y planes regionales de ordenación del territorio).

FIgURA 6 | Evolución de la superficie urbanizada normalizada en zona expuesta y no expuesta

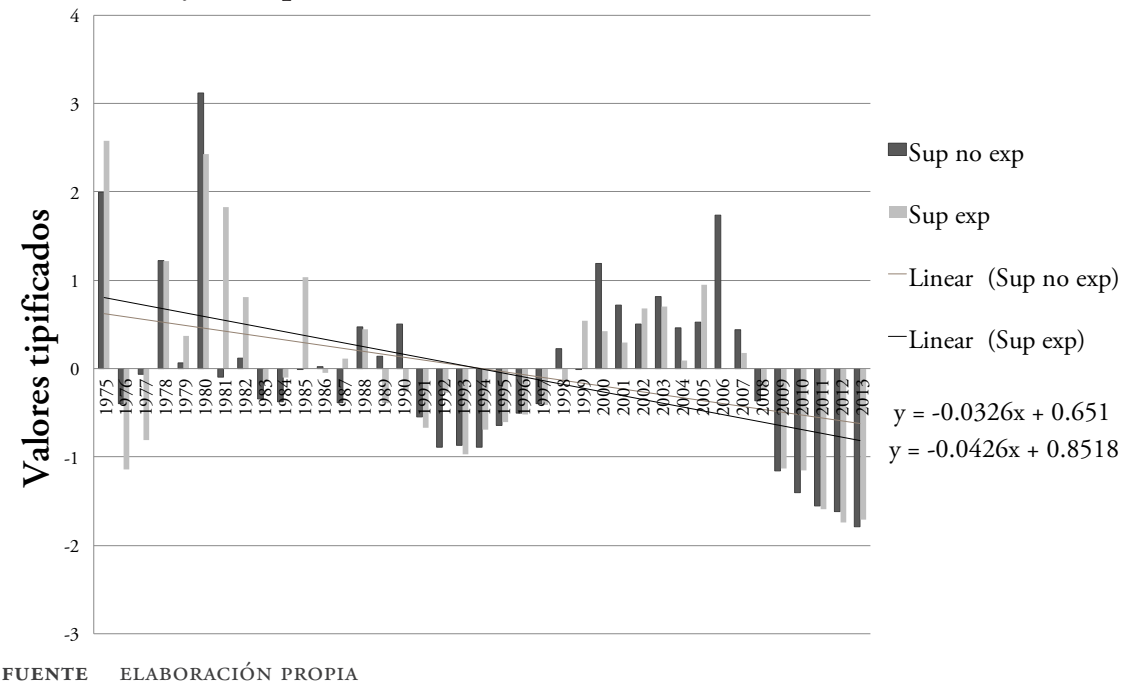


De acuerdo con todo lo anterior, se podría conjeturar que el aumento del riesgo en el área litoral de Alicante y Murcia se ha producido, básicamente, por incremento de la vulnerabilidad y la exposición ante el peligro de las inundaciones (figura 7).

FIGURA 7 Aumento de la exposición en dos poblaciones seleccionadas del área de estudio entre 1981 y 2013 . Izquierda, Jávea (Alicante), y derecha, San Javier (Murcia)
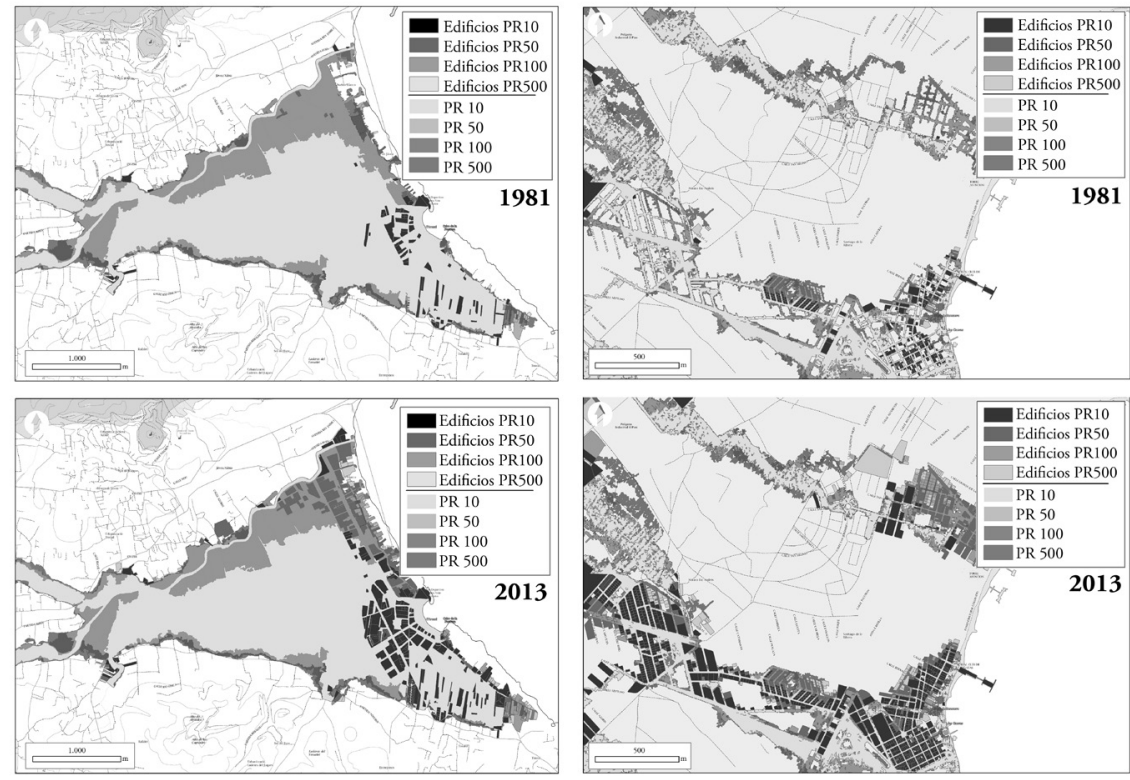

FUENTE ELABORACIÓN PROPIA

\section{El escaso protagonismo de la ordenación territorial como medida de reducción del riesgo de inundación}

El aumento de la exposición al peligro de inundaciones que se ha experimentado en la franja litoral de Alicante y Murcia en las cuatro últimas décadas ha motivado la puesta en marcha de medidas de reducción del riesgo para aminorar sus efectos. Básicamente, se han desarrollado medidas estructurales y de gestión de la emergencia, que han conseguido reducir, de modo significativo, las víctimas. Por el contrario, como ya se ha señalado, las pérdidas económicas originadas por las inundaciones no han dejado de aumentar en los últimos años, lo que manifiesta una efectividad muy baja tanto de las medidas estructurales realizadas, como de las no estructurales, que apenas se han puesto en marcha o aplicado. Se da el hecho significativo de que en episodios de lluvia intensa de poca cuantía ocurridos en los últimos años en la zona de estudio, se producen inundaciones con efectos económicos elevados.

Es posible evaluar la efectividad de las medidas de reducción del riesgo desarrolladas en el área de estudio atendiendo a su tipología y escala de actuación (tabla 3). 


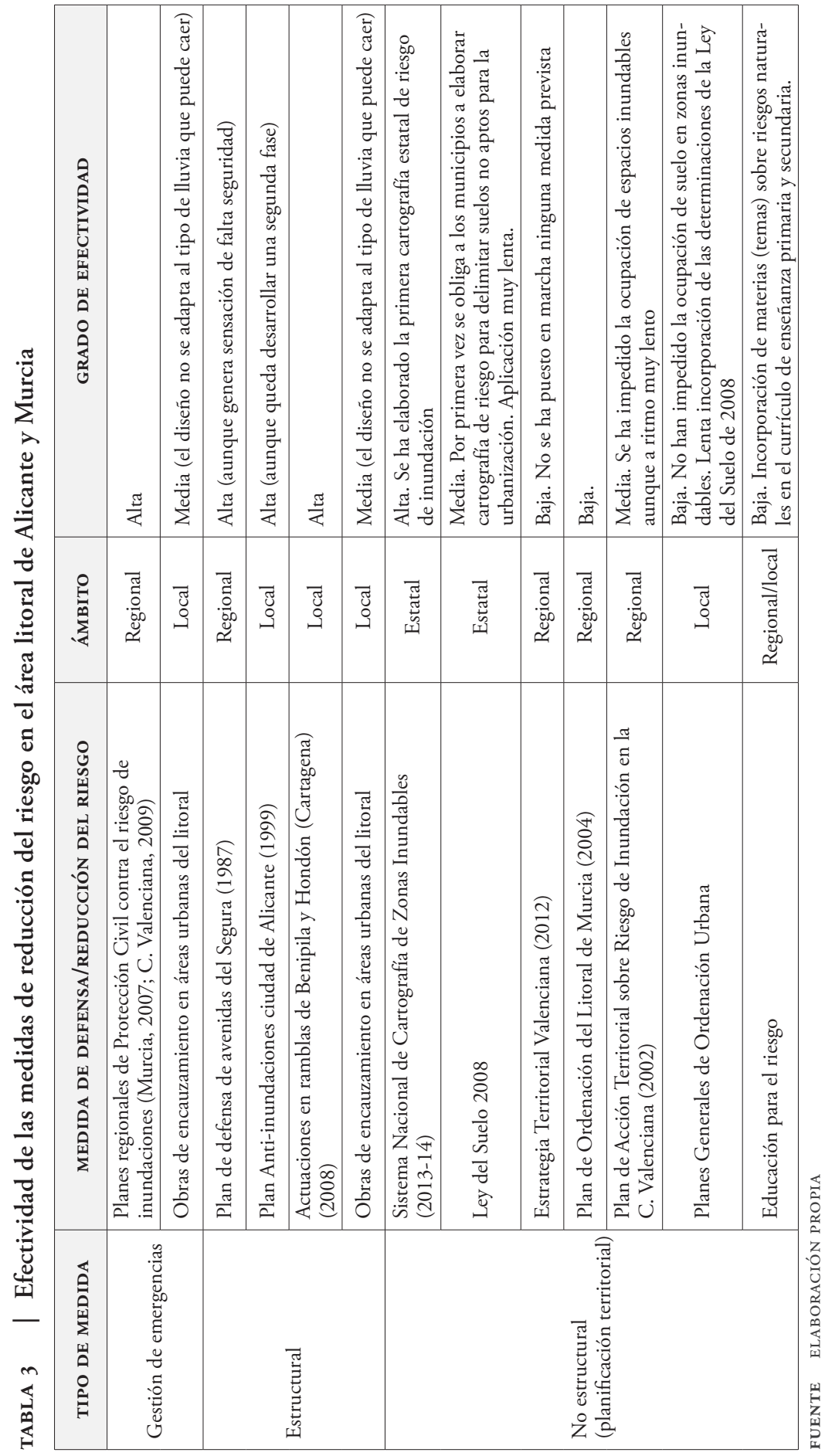


En su conjunto, las medidas de gestión de las emergencias, dependientes de los organismos regionales o locales de protección civil, son seguramente, las acciones que han contribuido en mayor orden a reducir el número de víctimas mortales. Hay un diseño muy eficaz de estrategias y protocolos de actuación y una integración bien estructurada de los distintos cuerpos y fuerzas de seguridad y protección civil.

En lo que se refiere a las estructurales, la más importante desarrollada ha sido la canalización del río Segura en sus tramos medio y bajo, incluida en el del Plan de Defensa de Avenidas de la cuenca del Segura (Ezcurra, 2007). Se creó un cauce nuevo, artificializado, con la finalidad de aumentar la capacidad de desagüe del agua de crecida fluvial hacia el mar. Como medidas complementarias, se llevaron a cabo obras de encauzamiento y construcción de colectores de pluviales de gran capacidad en Cartagena (ramblas de Benipila y Hondón). Independientemente de estas medidas, en la ciudad de Alicante, y tras las inundaciones de septiembre de 1997, se aprobó un Plan Anti-inundaciones que supuso la canalización de las principales ramblas y barrancos que atraviesan el término municipal. En sintonía con estas obras, se realizaron también actuaciones de control y rectificación de cauces naturales en núcleos urbanos del litoral de Alicante y Murcia, cuya construcción se aprobaba, generalmente, tras el desarrollo de un episodio de lluvias intensas (Denia, Calpe, Alfaz del Pí, Benidorm, Campello, Santa Pola, Orihuela, Pilar de la Horadada, Mazarrón, Águilas).

Por último, las no estructurales relacionadas con la ordenación del territorio, de acuerdo con los resultados de exposición del presente trabajo, han tenido una efectividad baja. En términos generales, se podría decir que existe un catálogo bien definido de políticas y documentos vinculantes que, de ser aplicados de forma eficiente y ordenada, podrían alcanzar una mitigación de la curva de exposición y, a buen seguro, de la de pérdidas. Sin embargo, gran parte del fracaso de este grupo de medidas reside en la ausencia de una cartografía integral de delimitación de zonas inundables, con la que hasta hace dos ańos los organismos públicos españoles de gestión del territorio todavía no contaban. Precisamente, el único aspecto positivo de este grupo de medidas ha sido la elaboración de una cartografía oficial de riesgo de inundación (Sistema Nacional de Cartografía de Zonas Inundables), en cumplimiento de lo establecido en la Directiva europea 60/2007 y que ha venido a cubrir la carencia antes señalada. El resto de planes de ordenación territorial, de escala regional, o los documentos de ordenación urbanística, de escala local, no han conseguido, hasta el momento, detener la ocupación de espacios con riesgo de inundación. Entre otras cosas, porque -como ya se ha indicado- la falta de cartografía dificultaba enormemente las políticas activas de deslinde de espacios inundables y eso se trasladó a una falta de asunción de competencias y confusión legislativa por parte de los organismos responsables (Ayala, 2002b; Olcina, 2004). El único plan que parece haber detenido, aunque en mínimo porcentaje, la ocupación de suelo en área inundable ha sido el Plan de Acción sobre Riesgo de Inundación en la Comunidad Valenciana (PATricova). Entre 2003, año de su aprobación, y 2012, se ha liberado una superficie de riesgo de 7.300 hectáreas inundables en Alicante (15\% del área inundable provincial), lo que supone un conjunto de población estimada 
en 25.000 habitantes en ese suelo desclasificado, mayoritariamente en municipios litorales de finalidad turística.

En lo que se refiere a la Región de Murcia, no existe un instrumento normativo similar. Lo más parecido es un documento de ordenación del territorio de su espacio litoral (Directrices y Plan de Ordenación del Litoral de la Región de Murcia), cuya eficiencia, en el sentido de la minimización del riesgo, ha sido prácticamente nula (Pérez, Gil-Guirado \& García, 2014).

Sin embargo, lo más llamativo en el análisis del incremento de la exposición al riesgo de inundación que se ha experimentado en los últimos veinte años en el área de estudio es la ineficacia absoluta que tuvo la Ley del Suelo de 1998, que por primera vez incluía un artículo (art. 9) que obligaba a clasificar como suelo "no urbanizable" aquel que tuviera "riesgo natural acreditado". Desafortunadamente, esta última condición fue utilizada por las administraciones locales como argumento para permitir la ocupación de espacios inundables, debido a que, ante un nuevo proyecto urbanizador, se justificaba la inexistencia de documentos oficiales que acreditasen el riesgo en un área determinada y acababa aprobándose su ocupación. Es decir, el gobierno estatal, pudiendo elaborar un instrumento capaz de organizar ese crecimiento desenfrenado, se sumó a la dinámica desarrollista de la manera más flagrante con la redacción de esta ley. En concreto, este instrumento del suelo abría tan claras oportunidades de financiación a los municipios por medio de visados de viviendas (Gaja, 2008) en sus ámbitos administrativos, que terminaron por representar una fuente suculenta de ingresos permanentes que, durante el periodo de crecimiento económico, nadie se atrevió a interrumpir. En términos espaciales, es fácil imaginar que el patrón de planificación seguido por la mayoría de las administraciones locales fue tratar de rentabilizar al máximo su superficie administrativa, ya fuese a expensas o no de lechos de inundación. En el área de estudio, este último aspecto fue incluso más sencillo, puesto que las ramblas y barrancos que drenan sus vertientes, debido a su condición de cauces efímeros o con caudal intermitente, invitaban a su ocupación, tal y como ya se ha mencionado anteriormente.

En la actualidad, la vigente Ley del Suelo estatal (2015), texto refundido del Real Decreto Legislativo (RDL) 2/2008, obliga a la elaboración de mapas de riesgo, con lo cual se desmorona esa "excusa" justificadora de la invasión de terrenos inundables. Debido a su juventud, no ha tenido aún efecto en los municipios litorales de Alicante y Murcia; pero, sobre todo, su posible influencia no ha dejado todavía constancia por el parón inmobiliario vivido desde el año 2008, que ha ralentizado, asimismo, la revisión de documentos de planeamiento urbano municipal y, con ello, la obligación de incluir mapas e informes de riesgo natural en los informes de sostenibilidad ambiental que tienen que acompañar estos nuevos documentos (figura 8). 
FIgURA 8 Procedimiento de incorporación del análisis de riesgo a los procesos de ordenación territorial y urbanística

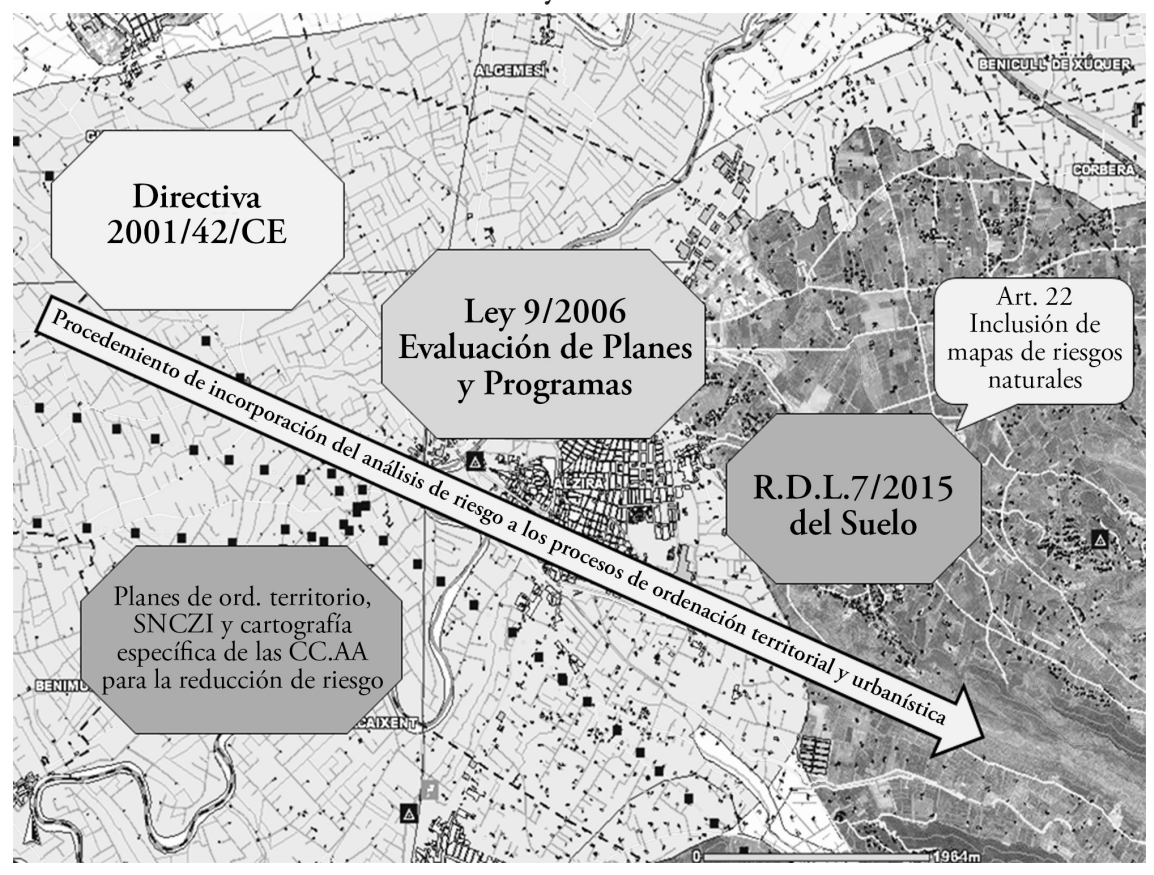

FUENTE ELABORACIÓN PROPIA

Otras medidas no estructurales orientadas a la reducción del riesgo natural, como la educación para el riesgo, se han desarrollado muy recientemente a partir de la incorporación de temas sobre esta cuestión en el currículo de enseñanzas primaria y secundaria, y su efectividad, orientada al medio y largo plazo, aún no puede ser evaluada.

\section{Conclusiones}

La información procedente del Catastro de Urbana, y su combinación con los datos contenidos en el Sistema Nacional de Cartografía de Zonas Inundables, arrojan unos resultados que invitan a pensar sobre su valía como herramienta eficaz para identificar, en escala de detalle, las áreas urbanizadas expuestas al peligro de inundaciones. De ser así, este método tiene potencialidad para aplicarse en otros ámbitos españoles con peligrosidad de inundación, lo que supone un verdadero paso adelante en las tareas de evaluación del riesgo en las que se apoyan los procesos de tomas de decisiones de carácter espacial.

En concreto, en el área de estudio, tras su aplicación ha resultado evidente el importante aumento de la exposición a zonas inundables. Esta situación ha seguido una evolución al ritmo de la coyuntura económica, con dos periodos de fuerte actividad inmobiliaria: el primero entre los años 1978 y 1982 y el segundo entre 1997 y 2007. Hasta la llegada de la crisis financiera global de 2008, el modelo económico 
basado en la promoción de la actividad inmobiliaria no presentaba signos de enfriamiento motivados por decisiones políticas.

En relación con el desarrollo de medidas contra inundaciones evaluadas, en lo que se refiere a las estructurales, parece que comienza a advertirse que los sectores donde tradicionalmente las inundaciones han producido crisis periódicas de extraordinaria gravedad tienen sistemas defensivos que permiten un umbral de seguridad aceptable; en la mayor parte de los casos, sin embargo, ello está aún por acreditarse. Por el contrario, la reciente e intensa ocupación de nuevos sectores ha generado nuevos espacios escasamente preparados ante estos eventos y, por tanto, muy vulnerables.

No obstante lo anterior, de sobra es sabido que la apuesta exclusiva por las medidas de carácter estructural no asegura en absoluto una mitigación generalizada del riesgo; es más, en ocasiones puede que suponga tan solo una migración del mismo hacia ámbitos desprotegidos, tal y como señaló White (1973). En estas circunstancias, la vulnerabilidad de las instituciones para proteger a la población tiene un papel protagonista en el cálculo global de vulnerabilidad, que debe ser analizado cuidadosamente. Habría que cuestionarse con más detenimiento sobre aspectos relativos a la forma en que esas instituciones abordan el problema de adaptación a las condiciones del medio, más que sobre la carrera por proteger lo desprotegido a medida que lo urbano se expone al peligro.

De hecho, de acuerdo con los resultados obtenidos, resulta muy llamativo que el periodo de retorno donde se ha construido de forma más intensa y en mayor cantidad sea el PRIO, algo que resulta poco explicable si consideramos las limitaciones de uso en dicha zona que se contienen en la legislación de aguas española.

Cabe aquí redirigir la búsqueda de responsabilidad de la naturaleza al deficiente papel de las administraciones competentes en ordenación territorial. Estas, dejándose llevar por los intereses económicos derivados de esta ocupación caótica de territorios expuestos al peligro (Romero, Jiménez \& Villoria, 2012), han obviado uno de los cometidos principales de su función: la reducción del riesgo en las poblaciones en peligro.

Los resultados obtenidos en el presente estudio coinciden con los que ya en su día apuntaban la Directiva Europea (Directiva 2007/60/CE, Parlamento Europeo, 2007) y el IPCC (2012 y 2014), que destacaban el incremento de los asentamientos humanos y bienes económicos en las llanuras aluviales entre los principales factores que han contribuido a elevar las probabilidades de inundaciones en el mundo, así como su impacto negativo. Resultados similares han alcanzado trabajos realizados con una metodología parecida en otros ámbitos de Europa (Jongman et al., 2014) y otros estudios que han manejado el análisis del usos del suelo (Rojas et al., 2013; Früh-Müller et al., 2014). Merece la pena, sin embargo, destacar que los valores de crecimiento del litoral sureste español son muy superiores, en línea con las cifras nacionales, que superan con creces a las de cualquier país europeo (Burriel, 2008).

Para terminar, conviene recordar que el análisis de riesgo, a escala de detalle, va a cobrar importancia en los próximos años, máxime si se tienen en cuenta los resultados de la modelización climática en latitudes medias y la posibilidad, bastante cierta, de que los episodios atmosféricos extremos sean más frecuentes en las próximas décadas (Rojas et al., 2013; IPCC, 2014). Desafortunadamente, al no 
disponer de tal información, este nivel de precisión no aplica por el momento para la gran mayoría de ámbitos urbanos. Se hace necesario, entonces, prestar atención y dedicar esfuerzos a obtener el tipo de coberturas señaladas, o al menos continuar con la cartografía de usos del suelo agregados.

\section{Referencias bibliográficas}

Abbot, J. (2005). Understanding and managing the unknown: The nature of uncertainty in planning. Journal of Planning Education and Research, 24 (3), 237-251. doi: $10.1177 / 0739456 \times 04267710$

Ayala, F .J. (2002a). La inundación torrencial catastrófica del camping "Las Nieves" del 7 de agosto de 1996 en el cono de deyección del Arás (Biescas, Pirineo Aragonés) (pp. 889-912). En F. J. Ayala Carcedo \& J. Olcina Cantos (Coords.), Riesgos Naturales. Barcelona: Ariel.

Ayala, F. J. (2002b). El sofisma de la imprevisibilidad de las inundaciones y la responsabilidad social de los expertos: un análisis del caso español y sus alternativas. Boletín de la Asociación de Geógrafos Españoles, (33), 79-92. En https://dialnet.unirioja.es/servlet/ articulo?codigo $=1122434$

Barredo, J. I. (2009). Normalised flood losses in Europe: 1970-2006. Natural Hazards and Earth System Science, 9 (1), 97-104. doi: 10.5194/nhess-9-97-2009

Barredo, J. I., Saurí, D. \& Llasat, M. C. (2012). Assessing trends in insured losses from floods in Spain 1971-2008. Natural Hazards and Earth System Science, 12 (5), 1723-1729. doi: 10.5194/nhess-12-1723-2012

Borup, M., Brown, N., Konrad, K. \& Van Lente, H. (2006). The sociology of expectations in science and technology. Technology Analysis \& Strategic Management, 18 (3/4), 285298. En http://dx.doi.org/10.1080/09537320600777002

Bouwer, L. M., Crompton, R. P., Faust, E., Hoppe, P. \& Pielke, R. A. Jr. (2007). Disaster management: Confronting disaster losses. Science, 318 (5851), 753. doi: 10.1126/ science. 1149628

Burriel, E. (2008. La década "prodigiosa" del urbanismo español (1997-2006). Scripta Nova. Revista Electrónica de Geografía y Ciencias Sociales [Número extraordinario dedicado al X Coloquio Internacional de Geocritica "Diez años de cambios en el mundo, en la geografia y en las ciencias sociales, 1999-2008”], 12 (270), 64. En http://www.ub.edu/geocrit/sn/ sn-270/sn-270-64.htm

Cardona, O., Van Aalst, M. K., Birkmann, J., Fordham, M., McGregor, G., R. Perez, R., Pulwarty, R. S., Schipper, L. F. \& Sinh, B. T. (2012). Determinants of risk: Exposure and vulnerability. En C. Field, V. Barros, T. F. Stocker \& D. Qin (Eds.), Managing the risks of extreme events and disasters to advance climate change adaptation. A Special Report of Working Groups I and II of the Intergovernmental Panel on Climate Change (IPCC) (pp. 65-108). Cambridge, uk, and New York: Cambridge University Press. 
Changnon, S. A., Pielke, R. A. Jr., Changnon, D., Sylves, R. T. \& Pulwarty, R. (2000). Human factors explain the increased losses from weather and climate extremes. Bulletin of the American Meteorological Society, 81 (3), 437-442. En http://journals.ametsoc.org/doi/ pdf/10.1175/1520-0477(2000)081\%3C0437\%3AHFETIL\%3E2.3.CO\%3B2

Consorcio de Compensación de Seguros. (2015). Estadística de riesgos extraordinarios. Madrid: Ministerio de Economía y Competitividad, 146. En http://cincodias.com/buscador/

De Moel, H. \& Aerts, J. C. J. H. (2011). Effect of uncertainty in land use, damage models and inundation depth on flood damage estimates. Natural Hazards, 58 (1), 407-425. doi: 10.1007/s11069-010-9675-6

De Moel, H., Aerts, J. C. \& Koomen, E. (2011). Development of flood exposure in the Netherlands during the 20th and 21st century. Global Environmental Change, 21 (2), 620-627. doi: 10.1016/j.gloenvcha.2010.12.005

De Roo, G. (2003). Environmental planning in the Netherlands: Too good to be true: From command and control planning to shared governance. Burlington, vT: Ashgate.

De Roo, G. \& Porter, G. (2007). Fuzzy planning the role of actors in a fuzzy governance environment. Aldershot, England; Burlington, vT: Ashgate.

Dirección General de Arquitectura, Vivienda y Suelo (DGAvs), España. (2014). Observatorio de Vivienda y Suelo. Boletín núm. 8, Cuarto cuatrimestre. Madrid: Centro de Publicaciones, Ministerio de Fomento.

Ezcurra, J. (2007). El Plan de Defensa contra Avenidas de 1987 en la cuenca del Segura. Plan de defensa de 1987 frente a avenidas en la cuenca del Segura. XX Aniversario, 13-33. Murcia: Confederación Hidrográfica del Segura/Ministerio de Medio Ambiente. En http://bit. ly/1ZpmCHh

Früh-Müller, A., Wegmann, M. \& Koellner, T. (2014). Flood exposure and settlement expansion since pre-industrial times in 1850 until 2011 in north Bavaria, Germany. Regional Environmental Change, 15 (1), 183-193. doi: 10.1007/s10113-014-0633-9

Gaja, F. (2008). El "tsunami urbanizador" en el litoral mediterráneo. El ciclo de hiperproducción inmobiliaria 1996-2006. Scripta Nova. Revista Electrónica de Geografía y Ciencias Sociales, 12 (270) (66). En http://www.ub.edu/geocrit/sn/sn-270/sn-270-66.htm

García, F. (2013). Una metodología para la delimitación y clasificación de las formas urbanas en las ciudades intermedias españolas durante el siglo xx basada en sig. Texto en actas del $V$ Seminario Internacional de Investigación en Urbanismo, Barcelona-Buenos Aires, junio 2013, 1199-1215. Barcelona: Departament d'Urbanisme i Ordenació del Territori (DUOT). En http://upcommons.upc.edu/handle/2099/14755

Gil-Guirado, S., Pérez, A. \& Barriendos, M. (2014). Increasing vulnerability to flooding in the southern Spanish Mediterranean coast (1960-2013). En Hydrological Extreme events in historic and prehistoric times, Bonn (Alemania). En http://bit.ly/1tmAbNm

Gil-Guirado, S., Pérez, A., Lopez, F. \& Barriendos, M. (2014). Review of flood alert thresholds based on the socioeconomic impact of catastrophic events in the southeastern Spain. En 4th EMS Annual Meeting and 10th European Conference on Applied Climatology (ECAC). Praga, República Checa.

Harrison, J. (2006). Economic crisis and democratic consolidation in Spain, 1973-82. Working Papers in Economic History, 06-10, 1-33.

Hooke, J. M. (2006). Human impacts on fluvial systems in the Mediterranean region. Geomorphology, 79 (3), 311-335. doi: 10.1016/j.geomorph.2006.06.036 
Instituto Nacional de Estadística (INE), España. (2013). Censos de Población y Viviendas 2011. Proyecto. (Marzo). Madrid. Autor. En http://www.ine.es/censos2011_datos/cen11_ datos_inicio.htm

Intergovernmental Panel on Climate Change (IPCC). (2012). Managing the risks of extreme events and disasters to advance climate change adaptation. En C. Field, V. Barros, T. F. Stocker \& D. Qin (Eds.), A Special Report of Working Groups I and II of the Intergovernmental Panel on Climate Change. Cambridge, uK, and New York: Cambridge University Press.

Intergovernmental Panel on Climate Change (IPCC). (2014). Climate change 2014: Synthesis report. En R. K. Pachauri \& L. A. Meyer (Eds.), Contribution of working groups I, II and III to the fifth assessment report of the intergovernmental panel on climate change. Geneva, Switzerland. En http://www.ipcc.ch/report/ar5/syr/

Jiménez, F. (2009). Building boom and political corruption in Spain. South European Society and Politics, 14 (3), 255-272. doi: 10.1080/13608740903356541

Jongman, B., Ward, P. J. \& Aerts, J. C. (2012a). Global exposure to river and coastal flooding: Long term trends and changes. Global Environmental Change, 22 (4), 823-835. En http://dx.doi.org/10.1016/j.gloenvcha.2012.07.004

Jongman, B., Kreibich, H., Apel, H., Barredo, J. I., Bates, P. D., Feyen, L., \& Ward, P. J. (2012b). Comparative flood damage model assessment: Towards a European approach. Natural Hazards and Earth System Science, 12 (12), 3733-3752. doi: 10.5194/ nhess-12-3733-2012

Jongman, B., Koks, E. E., Husby, T. G. \& Ward, P. J. (2014). Financing increasing flood risk: Evidence from millions of buildings. Natural Hazards and Earth System Sciences Discussions, 2 (1), 137-165. En http://dx.doi.org/10.5194/nhessd-2-137-2014

Koks, E. E., De Moel, H., Aerts, J. C. \& Bouwer, L. M. (2014). Effect of spatial adaptation measures on flood risk: study of coastal floods in Belgium. Regional environmental change, 14 (1), 413-425. doi: 10.1007/s10113-013-0514-7

Kron W. (2005). Flood risk = hazard • values • vulnerability. Water International, 30 (1), 58-68. doi: $10.1080 / 02508060508691837$

Llasat, M. C., López, L., Barnolas, M. \& Llasat-Botija, M. (2008). Flash-floods in Catalonia: The social perception in a context of changing vulnerability. Advances in Geosciences, 17, 63-70, doi: 10.5194/adgeo-17-63

Luhmann, N. (1979). Trust and power: two works. Chichester, NY: Wiley.

Ministerio de Agricultura, Alimentación y Medio Ambiente (MAgrama), España. (5 de 10 de 2014). Sistema Nacional de Cartografia de Zonas Inundables. Recuperado el 5 de 4 de 2014, de Sistema Nacional de Cartografía de Zonas Inundables. En http://www. magrama.gob.es/es/agua/temas/gestion-de-los-riesgos-de-inundacion/snczi/

Meyer, V., Becker, N., Markantonis, V., Schwarze, R., Van den Bergh, J. C. J. M., Bouwer, L. M., \& Viavattene, C. (2013). Review article: Assessing the costs of natural hazardsstate of the art and knowledge gaps. Natural Hazards and Earth System Science, 13 (5), 1351-1373. doi: 10.5194/nhess-13-1351-2013

Ministerio de Hacienda y Administraciones Públicas (MHAP), España. (08-08-2014). Dirección General del Catastro. Recuperado el 08 de 05 de 2014, de Dirección General del Catastro. En http://www.sedecatastro.gob.es/ 
Olcina, J. (2004). Riesgo de inundaciones y ordenación del territorio en la escala local El papel del planeamiento urbano municipal. Boletín de la Asociación de Geógrafos Españoles, 37 (monográfico "Agua y Ciudad”), 49-84.

Olcina, J. (2007). La consideración del peligro de inundaciones en los procesos de planificación territorial. En J. Olcina (Ed.), Riesgo de inundaciones y ordenación del territorio en España (pp. 105-116). Alicante: Fundación Instituto Euromediterráneo del Agua.

Olcina, J. (2009). Cambio climático y riesgos climáticos en España. Investigaciones Geográficas, 49, 197-220. doi: 10.14198/INGEO2009.49.10

Pérez, A. (2008). Aumento del riesgo de inundación por ocupación indebida de las áreas de convergencia de aguas en el sur de la Región de Murcia. Scripta Nova: Revista Electrónica de Geografía y Ciencias Sociales, 12 (270), (27). En http://www.ub.edu/ geocrit/sn/sn-270/sn-270-27.htm

Pérez, A., Gil-Guirado, S. \& García, F. (2014). Veinte años de protección de cauces en el litoral de la Región de Murcia (1994-2013). Evaluación de la eficiencia de las medidas de Ordenación del Territorio. En A. Serrano (Ed.), 7th International Congress for Spatial Planning (pp. 242-253). Madrid: Fundicot (Asociación Interprofesional de Ordenación del Territorio).

Poussin, J. K., Bubeck, P., Aerts, J. C. J. H. \& Ward, P. J. (2012). Potential of semi-structural and non-structural adaptation strategies to reduce future flood risk: Case study for the Meuse. Natural Hazards and Earth System Science, 12 (11), 3455-3471. En http:// www.preventionweb.net/publications/view/30456

Prados, L. \& Sanz, J. C. (1996). Growth and macroeconomic performance in Spain, 1939-93. En N. Crafts \& G. Toniolo (Eds.), Economic Growth in Europe since 1945 (pp. 355387). Cambridge: Cambridge University Press. En http://dx.doi.org/10.1017/ CBO9780511758683.013

Rojas, R., Feyen, L. \& Watkiss, P. (2013). Climate change and river floods in the European Union: Socio-economic consequences and the costs and benefits of adaptation. Global Environmental Change, 23 (6), 1737-1751. En http://dx.doi.org/10.1016/j. gloenvcha.2013.08.006

Romero, J., Jiménez, F. \& Villoria, M. (2012). (Un)sustainable territories: Causes of the speculative bubble in Spain (1996-2010) and its territorial, environmental, and sociopolitical consequences. Environment and Planning C: Government and Policy, 30 (3), 467-486. En https://ideas.repec.org/s/pio/envirc.html

Saurí, D., Serra A., Olcina, J. \& Vera, J.F. (2011). Climate change and Europe’s regions: Key findings. Case study Spanish Mediterranean coast. En S. Greiving (Coord.), ESPON Climate Change and Territorial Effects on Regions and Local Economies (pp. 30-39). En http://bit.ly/1tmzTG7

Serra-Llobet, A., Tàbara, J. D. \& Saurí, D. (2013). The Tous dam disaster of 1982 and the origins of integrated flood risk management in Spain. Natural hazards, 65 (3), 19811998. doi: 10.1007/s11069-012-0458-0

Symeonakis, E., Calvo-Cases, A. \& Arnau-Rosalen, E. (2007). Land use change and land degradation in southeastern Mediterranean Spain. Environmental management, 40 (1), 80-94. doi: 10.1007/s00267-004-0059-0 
Te Linde, A. H., Bubeck, P., Dekkers, J. E. C., De Moel, H. \& Aerts, J. C. J. H. (2011). Future flood risk estimates along the river Rhine. Natural Hazards and Earth System Sciences, 11 (2), 459-473. doi: 10.5194/nhess-11-459-2011

Van Renssen, S. (2013). eu adaptation policy sputters and starts. Nature Climate Change, 3 (7), 614-615. doi: 10.1038/nclimate1943

White, G. F. (1973). Natural hazards research. En R. J. Chorley (Ed.), Directions in geography (pp. 193-216). London: Metheun.

World Meteorological Organization (wмо), Centre for Research on the Epidemiology of Disasters (CRED) \& Université Catholique de Louvain (UCL). (2014). Atlas of Mortality and Economic Losses from Weather, Climate and Water Extremes 1970-2012. Geneva, Switzerland: wMO. 